\title{
Comparison Between MRAS and SMO Based Sensorless Control Methods of Permanent Magnet Synchronous Motor
}

\author{
Çağlar Aydın ${ }^{1+} \mathbb{D}$, Sencer Ünal ${ }^{2}$ (D),Mehmet Özdemir ${ }^{3}$ (D) \\ ${ }^{1 *}$ Firat University, Electrical and Electronics Engineering Department, Elazı̆̆, Turkey. (e-mail: caglaraydin217@gmail.com). \\ ${ }^{2}$ Firat University, Electrical and Electronics Engineering Department, Elazığ, Turkey. (e-mail: sencerunal@ firat.edu.tr). \\ ${ }^{3}$ Firat University, Electrical and Electronics Engineering Department, Elazığ, Turkey. (e-mail: mozdemir@ firat.edu.tr).
}

\section{ARTICLE INFO}

Received: Oct., 16. 2020

Revised: May., 22. 2021

Accepted: May, 23.2021

Keywords:

Pmsm

Mras

Smo

Sensorless

Corresponding author: Çă̆lar Aydın

ISSN: 2536-5010 | e-ISSN: 2536-5134

\section{ABSTRACT}

This paper presents a comparison between sliding mode observer and model reference adaptive system based sensorless position and speed control of permanent magnet synchronous motor. In traditional sliding mode observers, signum function, which is used as switching function, causes chattering effect. To reduce chattering effect, low pass filter is used but this filter introduces a phase delay. In order to eliminate these problems, a sigmoid function is used instead of signum function in sliding mode observer based control method. In model reference adaptive system based control method, it is purposed to make error zero between the reference model and adjustable model. Popov's super stability theorem is used for the stability of model reference adaptive system control method. Both of the control methods are simulated with Matlab/Simulink.

DOI: https://doi.org/10.36222/ejt.811569

\section{INTRODUCTION}

Permanent magnet synchronous motors (PMSM) are widely used in high performance applications for its advantages such as high power density, high efficiency, high torque to inertia ratio and robustness. In earlier control applications, direct current (DC) machines were used because of that flux and torque of DC machines could be controlled separately. But DC machines increase operation and maintenance cost due to the presence of commutator and brushes and they can not operate in explosive and hazard conditions due to sparking occurs at brushes. In last decades, applying vector control [1-2] and developments in power electronic devices allowed induction machines as an important alternative to the DC machines. However in comparison with induction machine, PMSM, which is another alternative current (AC) machine, has some advantages such as high power factor, high efficiency and decreased rotor losses [3-4].

In order to use PMSM with high efficiency, absolute position and speed information have to be obtained. For this purpose, position and speed sensors such as tachogenerator, resolver and encoder are generally used. Due to disadvantages of these sensors such as bigger motor size, higher cost and complexity, sensorless control method has recently attracted an important attention.

In Fig. 1, sensorless field oriented control (FOC) is used to control the torque and magnetic flux of the motor separately. Flux and torque are controlled respectively by $i_{d}$ and $i_{q}$ currents. In this control, the error signal is obtained from the difference between the reference and estimated values and then the error is processed through a PI controller.

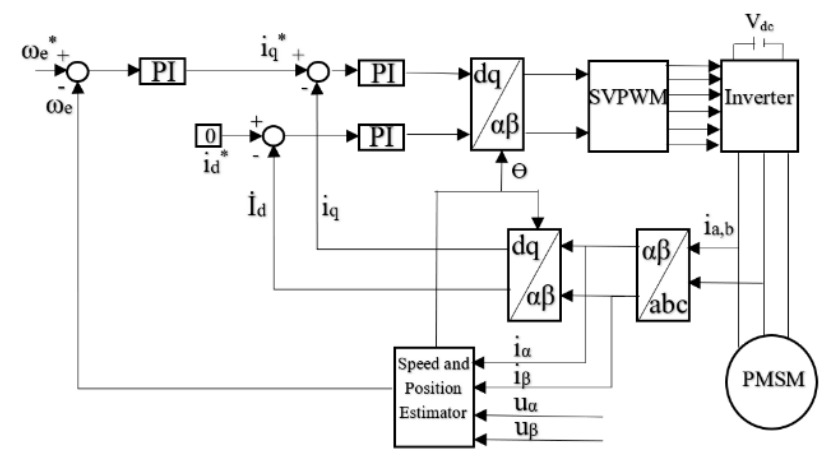

Figure 1. Block diagram of sensorless FOC of PMSM 
Sensorless control methods of PMSM can be divided into two main categories:

- Model based sensorless methods

- High frequency (HF) signal injection based methods

Model based control methods require measurement of stator voltages and currents to estimate the back electromotive force (EMF) for position and speed information. Model based methods are generally used in medium and high speed operations. In these methods, position and speed information is contained by the back EMF and so in low speed operations, in which back EMF magnitude is not sufficiently large to measure, position and speed information can not measure accurately. Main techniques of the model based control methods are; sliding mode observer (SMO), model reference adaptive system (MRAS) and extended Kalman filter (EKF) [5-6].

HF signal injection methods use magnetic saliency (anisotropy) of the machine, which is a result of saturation and geometric construction, for position and speed information. In signal injection methods generally two techniques are used: high frequency signal injection method and pulse injection method. In surfaced mounted PMSM, rotor position does not change according to the stator inductances and so HF signal injection can not be used in these motors. HF signal injection methods are used in standstill and low speed operations; because in high speed operation they need very high frequency [7-9].

In this paper SMO and MRAS based control methods are compared. In order to eliminate chattering effect caused by signum switching function in SMO based control method, without using a low pass filter, a sigmoid function is used to get accurate position and speed information. Owing to sigmoid function, it has also been observed a decrease in noise and ripple of the system. In MRAS based method, PMSM itself is chosen as reference model and current model as adjustable model. Adjustable model variables are adjusted through adaption mechanism to estimate accurate position and speed information. According to results, it is observed that a decrease in the noise and ripple of the torque and speed curves.

\section{MODELLING OF PMSM}

d-q axis equivalent circuit models are as in Fig. 2:

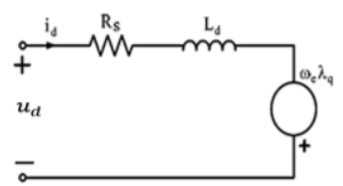

(a)

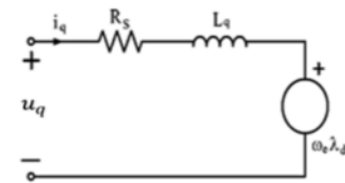

(b)
Figure 2. Equivalent circuit models of PMSM in rotor reference frame (a) daxis and (b) q-axis

Flux equations in rotor reference frame (1), (2):

$$
\begin{gathered}
\lambda_{q=} L_{q} i_{q} \\
\lambda_{d}=L_{d} i_{d}+\lambda_{m}
\end{gathered}
$$

Voltage equations in (3), (4):

$$
\begin{gathered}
u_{d}=R_{s} i_{d}+p \lambda_{d}-\omega_{e} \lambda_{q} \\
u_{q}=R_{s} i_{q}+p \lambda_{q}+\omega_{e} \lambda_{d}
\end{gathered}
$$

In equation (3), (4); $u_{d}$ and $u_{q}$ are the $\mathrm{d}$-q axis voltages, $p$ is the derivative operator, $i_{d}$ and $i_{q}$ are the $\mathrm{d}$-q axis currents, $\lambda_{d}$ and $\lambda_{q}$ are the $\mathrm{d}$-q axis fluxes and $\lambda_{m}$ is the permanent magnet flux.

Electromagnetic torque produced by PMSM is (5):

$$
T_{e}=\frac{3 p}{2}\left[\lambda_{m} i_{q}+\left(L_{d}-L_{q}\right) i_{d} i_{q}\right]
$$

First part of the Eq. 5 shows the torque produced by permanent magnets and second part of the Eq. 5 shows the reluctance torque. In surfaced mounted PMSM, reluctance torque is equal to zero because $\mathrm{d}$ and $\mathrm{q}$ axis inductance have the same value. Mechanical torque is as in Eq. 6;

$$
T_{m}=j p \omega_{m}+B \omega_{m}+T_{L}
$$

In Eq. 6, $\omega_{m}$ is mechanical speed, $j$ is moment of inertia and $T_{L}$ is load torque.

\section{SENSORLESS CONTROL METHODS OF PMSM}

\subsection{Sliding mode observer}

Sliding mode control is a control method that changes dynamics of nonlinear systems using HF switching functions [10-11]. For estimation of speed and position information of a PMSM, sliding mode control is used as an observer. SMO is one of the back EMF based estimation methods.

Fig. 3 shows the behaviour of the system states in SMO:

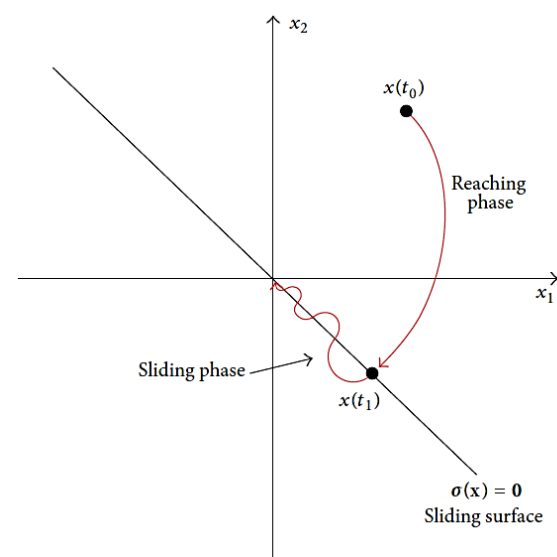

Figure 3. The behaviour of the system states in SMO [13]

Fig. 3 shows that SMO forces state variables to the sliding surface and then controls the system to maintain position of the state variables on the sliding surface. The main purpose of this control is to make the sliding surface variable $(\sigma(x))$ zero. The first step for controller is to choose a sliding surface. Then a reaching phase and a sliding phase occur. Reaching phase begins with the initial state and continues to end of the 
switching state. During the reaching phase, state variables are led to sliding phase. In sliding phase state variables are hold on sliding surface and led to equilibrium point [12].

In SMO based control to reach the the sliding surface, an infinite switching frequency is needed. But it is not possible to use an infinite switching frequency. This situation is called as chattering effect and causes estimation errors. Chattering effect also causes noise and oscillation in the system. To eliminate this effect, a low pass filter is used but filters cause a phase delay [14]. To keep up phase delay at minimum level, filter designing has an important effect. Another solution to eliminate chattering effect is to use a sigmoid function instead of signum function.

Current equations $(a-\beta$ coordinates $)$ in stationary reference frame in $(7),(8)$ :

$$
\begin{gathered}
\frac{d}{d t} i_{\alpha}=-\frac{R_{S}}{L_{S}} i_{\alpha}+\frac{1}{L_{S}} u_{\alpha}-\frac{\lambda_{m}}{L_{S}} \omega_{r} \sin \theta_{r} \\
\frac{d}{d t} i_{\beta}=-\frac{R_{S}}{L_{S}} i_{\beta}+\frac{1}{L_{S}} u_{\beta}-\frac{\lambda_{m}}{L_{S}} \omega_{r} \cos \theta_{r}
\end{gathered}
$$

Back EMF equations in (9), (10):

$$
\begin{aligned}
& e_{\alpha}=-\lambda_{m} \omega_{r} \cos \theta_{r} \\
& e_{\beta}=\lambda_{m} \omega_{r} \sin \theta_{r}
\end{aligned}
$$

Using stationary reference frame equations of PMSM, Eq. (11) and (12) is obtained:

$$
\begin{aligned}
& \frac{d}{d t} \widehat{\iota_{a}}=-\frac{R_{S}}{L_{S}} \widehat{\iota_{a}}+\frac{1}{L_{S}} u_{\alpha}-K_{s w} \frac{1}{L_{S}} H\left(\widehat{\iota_{a}}-i_{a}\right) \\
& \frac{d}{d t} \widehat{\iota_{\beta}}=-\frac{R_{S}}{L_{S}} \widehat{\iota_{\beta}}+\frac{1}{L_{S}} u_{\beta}-K_{S w} \frac{1}{L_{S}} H\left(\widehat{\iota_{\beta}}-i_{\beta}\right)
\end{aligned}
$$

The error between reference and estimated values is $\widetilde{\imath_{s}}=\widehat{\imath_{s}}-i_{s}$

$$
\begin{gathered}
H\left(\tilde{\imath_{a}}\right)=\left(\frac{2}{1+\exp \left(-a \tilde{\iota_{a}}\right)}\right)-1 \\
H\left(\tilde{\iota_{\beta}}\right)=\left(\frac{2}{1+\exp \left(-a \tilde{\iota_{\beta}}\right)}\right)-1
\end{gathered}
$$

Lyupanov function is used for stability of the observer.

$$
V=\frac{1}{2}\left({\widetilde{\iota_{a}}}^{2}+{\widetilde{\iota_{\beta}}}^{2}\right)
$$

$$
\begin{gathered}
\frac{d}{d t} V=-\frac{R_{S}}{L_{S}}\left(\tilde{\iota}_{a}^{2}+{\tilde{\iota_{\beta}}}^{2}\right)+\frac{1}{L_{S}}\left(e_{\alpha} \tilde{\iota_{a}}+e_{\beta} \tilde{\iota_{\beta}}\right. \\
-\frac{K_{S w}}{L_{S}}\left(\left|\tilde{\iota_{a}}\right|+\left|\tilde{\iota_{\beta}}\right|\right)
\end{gathered}
$$

When observer reached the sliding surface, estimated current values turn into reference frame. Then current equations are $\tilde{\imath_{a}}=0$ and $\tilde{\iota_{\beta}}=0$.

$$
\begin{aligned}
& \widehat{e_{a}}=K_{s w} H\left(\widetilde{l_{a}}\right) \\
& \widehat{e_{\beta}}=K_{s w} H\left(\widetilde{l_{\beta}}\right)
\end{aligned}
$$

Fig. 4 shows block diagram of SMO with sigmoid function:

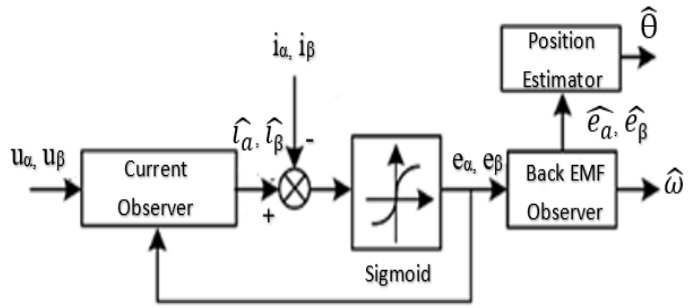

Figure 4. Block diagram of SMO with sigmoid function

In Eq. (19) rotor position:

$$
\hat{\theta}=-\tan ^{-1}\left(\frac{\widehat{e_{a}}}{\widehat{e_{\beta}}}\right)
$$

In Eq. (20) rotor speed:

$$
\widehat{\omega_{r}}=\frac{d \hat{\theta}}{d t}
$$

Fig. 5 shows Matlab/Simulink model of SMO.

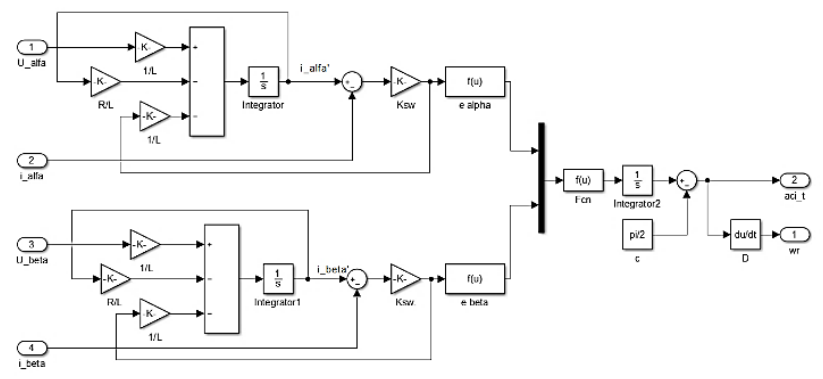

Figure 5. Matlab/Simulink model of SMO

\subsection{Model reference adaptive system}

MRAS is a closed loop control method to estimate position and speed of PMSM. MRAS has three main models: reference model, adjustable model and adaption mechanism. Reference model is independently of the variable and it does not contain unknown parameters. Adjustable model is dependent on variable being estimated. The adaption mechanism uses the difference between the two models to tune the estimated 
variable and feed it back to the adjustable model [14]. Adaption mechanism controls adjustable model through a PI controller [15-17]. In this paper PMSM itself is chosen as reference model and current model of PMSM is chosen as adjustable model. Fig. 6 shows structure of MRAS.

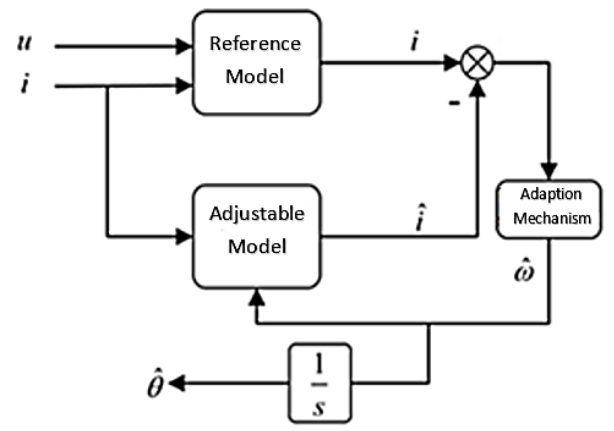

Figure 6. Structure of MRAS

According to the mathematical model of PMSM in the d-q coordinate system, the current model of the stator can be described as [17]:

$$
\begin{gathered}
\frac{d}{d t}\left[\begin{array}{c}
i_{d}+\frac{\lambda_{m}}{L} \\
i_{q}
\end{array}\right]=\left[\begin{array}{cc}
-\frac{R_{s}}{L} & \omega_{e} \\
-\omega_{e} & -\frac{R_{s}}{L}
\end{array}\right]\left[\begin{array}{c}
i_{d}+\frac{\lambda_{m}}{L} \\
i_{q}
\end{array}\right]+\frac{1}{L}\left[\begin{array}{c}
u_{d}+\frac{R_{s} \lambda_{m}}{L} \\
u_{q}
\end{array}\right] \\
i_{d}^{*}=i_{d}+\frac{\lambda_{m}}{L}, \quad i_{q}^{*}=i_{q} \\
u_{d}^{*}=u_{d}+\frac{R_{s} \lambda_{m}}{L}, \quad u_{q}^{*}=u_{q}
\end{gathered}
$$

MRAS reference model can be described:

$$
\frac{d}{d t}\left[\begin{array}{l}
i_{d}^{*} \\
i_{q}^{*}
\end{array}\right]=\left[\begin{array}{cc}
-\frac{R_{s}}{L} & \omega_{e} \\
-\omega_{e} & -\frac{R_{s}}{L}
\end{array}\right]\left[\begin{array}{l}
i_{d}^{*} \\
i_{q}^{*}
\end{array}\right]+\frac{1}{L}\left[\begin{array}{l}
u_{d}^{*} \\
u_{q}^{*}
\end{array}\right]
$$

MRAS adjustable model can be described as:

$$
\frac{d}{d t}\left[\begin{array}{l}
i_{d}^{\wedge} \\
i_{q}^{\wedge}
\end{array}\right]=\left[\begin{array}{cc}
-\frac{R_{s}}{L} & \omega_{e} \\
-\omega_{e} & -\frac{R_{s}}{L}
\end{array}\right]\left[\begin{array}{l}
i_{d}^{\wedge} \\
i_{q}^{\wedge}
\end{array}\right]+\frac{1}{L}\left[\begin{array}{l}
u_{d}^{*} \\
u_{q}^{*}
\end{array}\right]
$$

The error between the reference model and adjustable model can be written as: $e=i^{*}-i^{i}$

$$
\begin{gathered}
p e=A e-W I \\
v=D e \\
D=I \text { and then } \quad v=e
\end{gathered}
$$

According to Popov Super Stability Theory:

(1) Transfer matrix $\mathrm{H}(\mathrm{s})=\mathrm{D}(\mathrm{sI}-\mathrm{A})^{-1}$ must be positive real matrix,

(2) $\eta\left(0, t_{0}\right)=\int_{0}^{t_{0}} v^{T} W d t \geq-\gamma_{0}^{2}, \quad \forall t_{0} \geq 0, \quad \gamma_{0}^{2}>0$ is any finite positive number.

Then, $\lim _{t \rightarrow \infty} e(t)=0$, the MRAS is asymptotically stable.

$\widehat{\omega}$ can be obtained as:

$\widehat{\omega}=\int_{0}^{t_{0}} k_{1}\left(i_{d}^{*} i_{q}^{\wedge}-i_{q}^{*} i_{d}^{\wedge}\right) d \tau+k_{2}\left(i_{d}^{*} i_{q}^{\wedge}-i_{q}^{*} i_{d}^{\wedge}\right)+\widehat{\omega}(0)$

When $k_{1}$ and $k_{2} \geq 0$

$\widehat{\omega}=k_{1}^{\wedge} \int_{0}^{t_{0}}\left[i_{d}^{*} i_{q}^{\wedge}-i_{q}^{*} i_{d}^{\wedge}-\frac{\lambda_{f}}{L}\left(i_{q}^{*}-i_{q}^{\wedge}\right)\right] d \tau+k_{2}^{\wedge}\left[i_{d}^{*} i_{q}^{\wedge}-i_{q}^{*} i_{d}^{\wedge}-\right.$

$\left.\frac{\lambda_{f}}{L}\left(i_{q}^{*}-i_{q}^{\wedge}\right)\right]+\widehat{\omega}(0)$

Rotor position is defined as integral of speed (Eq. 31):

$$
\theta_{e}=\int_{0}^{t_{0}} \widehat{\omega} d t
$$

Fig. 7 shows Simulink model of adjustable model:

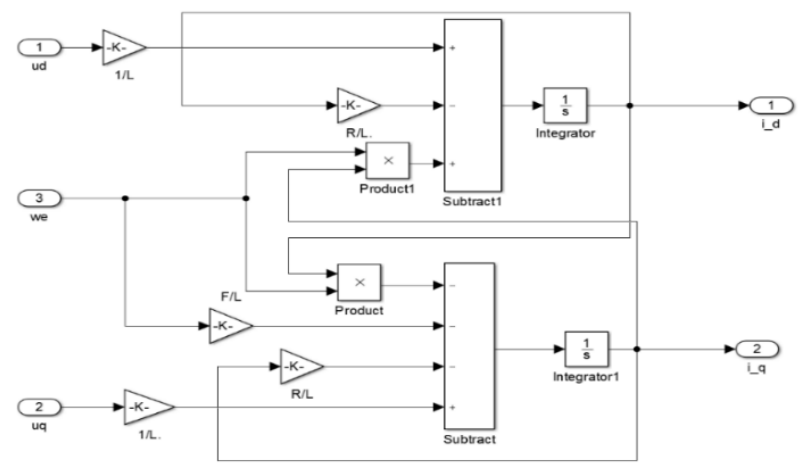

Figure 7. Adjustable Model

Fig. 8 shows Simulink model of adaption mechanism:

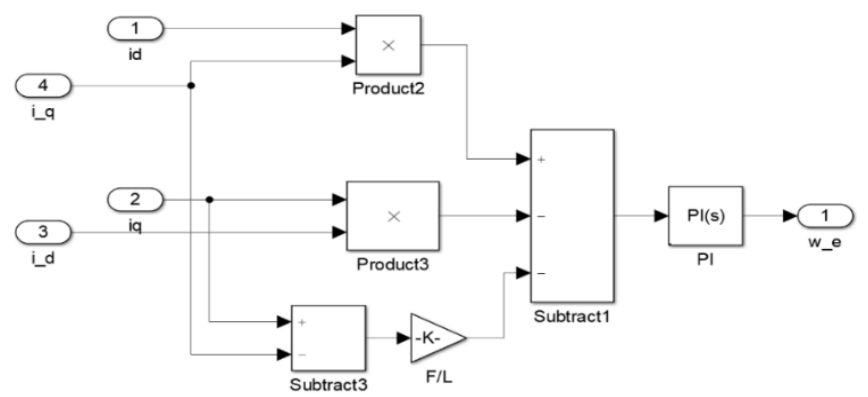

Figure 8. Adaption Mechanism 


\section{SIMULATION RESULTS}

Table 1 shows simulation parameters of the PMSM model:

TABLE I

\begin{tabular}{|l|l|}
\hline PARAMETERS & VALUES \\
\hline Stator resistance $\left(R_{s}\right)$ & $2.8175 \Omega$ \\
\hline Pole Pairs $(p)$ & 2 \\
\hline d-axis inductance $\left(L_{d}\right)$ & $0.0085 \mathrm{H}$ \\
\hline q-axis inductance $\left(L_{q}\right)$ & $0.0085 \mathrm{H}$ \\
\hline Rotor flux linkage $\left(\lambda_{m}\right)$ & $0.175 \mathrm{~Wb}$ \\
\hline Moment of inertia $(J)$ & $0.0008 \mathrm{kgm}^{2}$ \\
\hline
\end{tabular}

PARAMETERS of PMSM

In Fig. 9, reference speed is $1000 \mathrm{rpm}$ and load torque is 5 $\mathrm{Nm}$ for $0-0,5 \mathrm{~s}$ and it is shown that speed, torque, phase currents and position error simulation results of SMO and MRAS based models and their comparison.

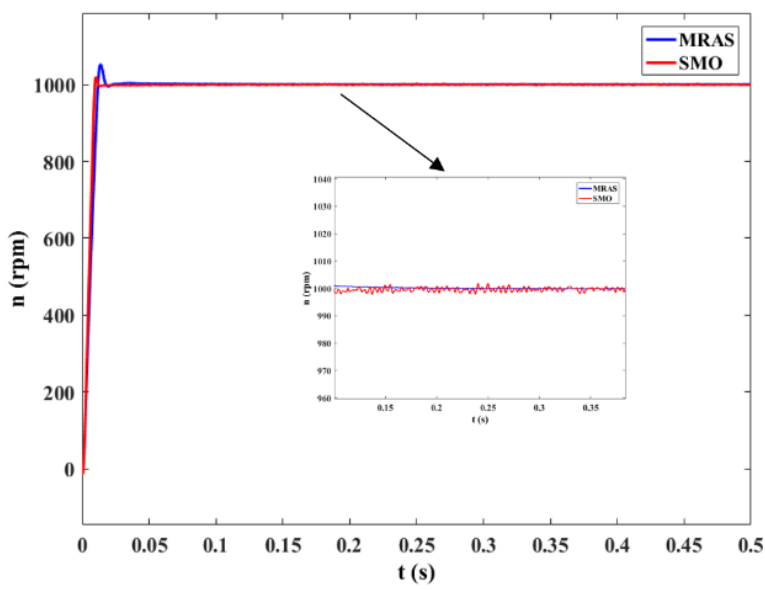

(a)

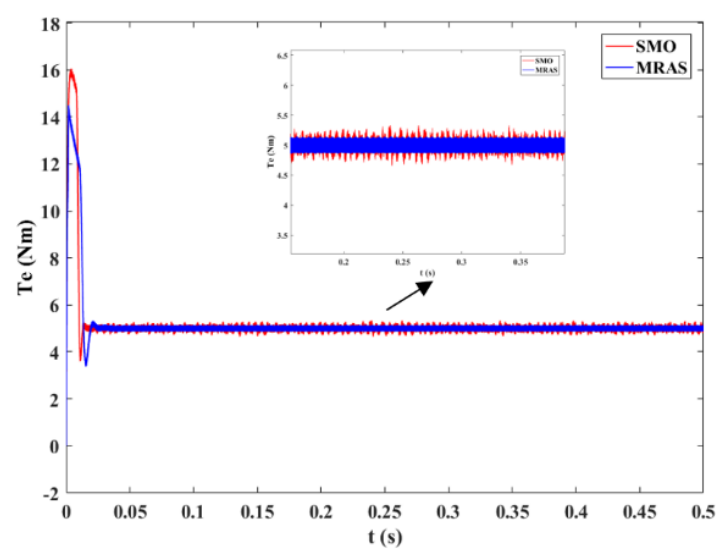

(b)

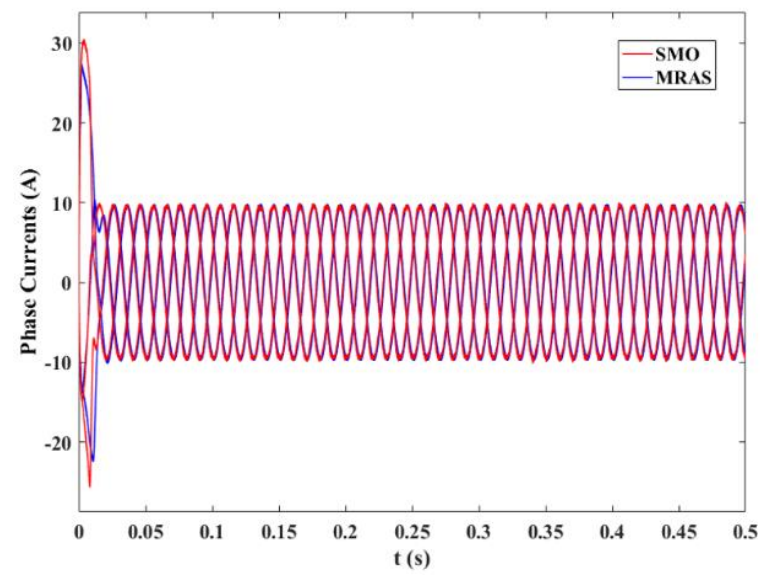

(c)

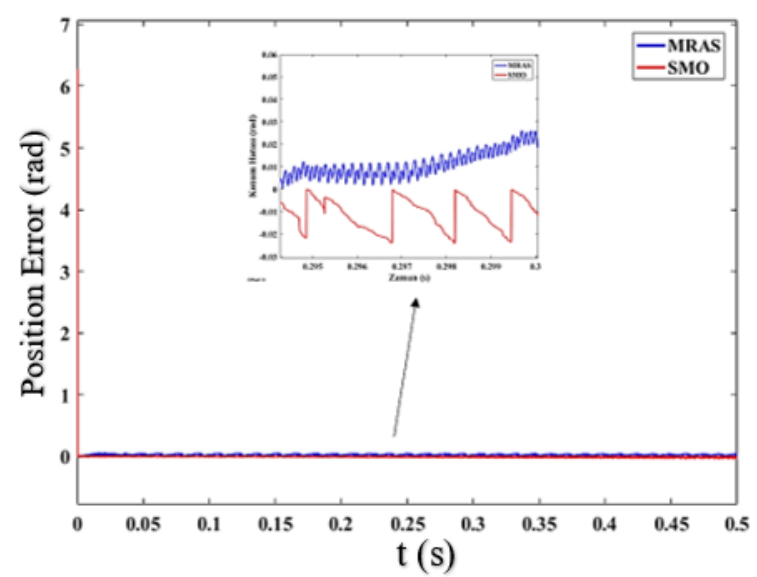

(d)

Figure 9. Speed, torque, phase currents and position error graphics of PMSM for $1000 \mathrm{rpm}$ and $5 \mathrm{Nm}$

In Fig. 9.a, MRAS based control method speed response has $5 \%$ overshoot and $0.03 \mathrm{~s}$ settling time while SMO based control method has $2 \%$ overshoot and 0.09 s settling time. In Fig 9.d, position error in MRAS based control is $0.039 \mathrm{rad}$ while in SMO based is $0.035 \mathrm{rad}$.

In Fig. 10 shows the speed of PMSM as the reference is changed 500-1000-1500 rpm at 0-0.15-0.35 s and load torque is $5 \mathrm{Nm}$ at 0-0,5 s. In Fig. 10, it is shown that speed, torque, phase currents and position error simulation results of SMO and MRAS based models and their comparison.

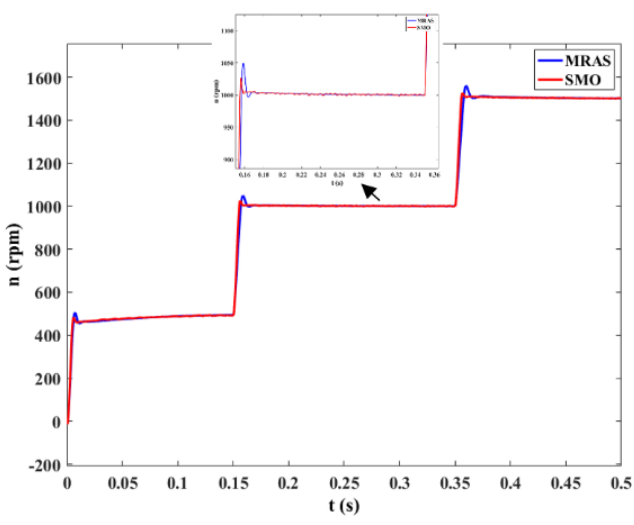

(a) 


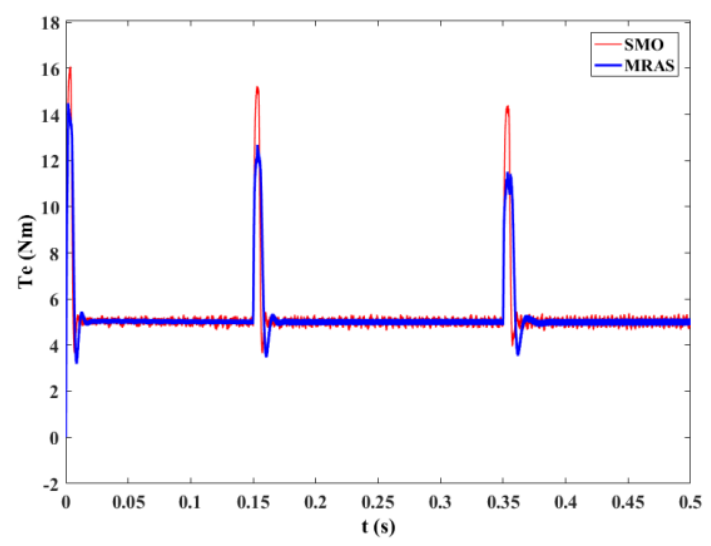

(b)

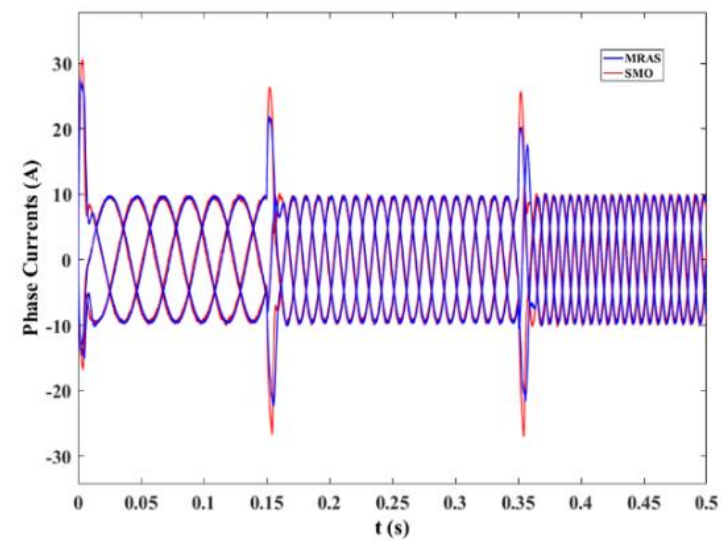

(c)

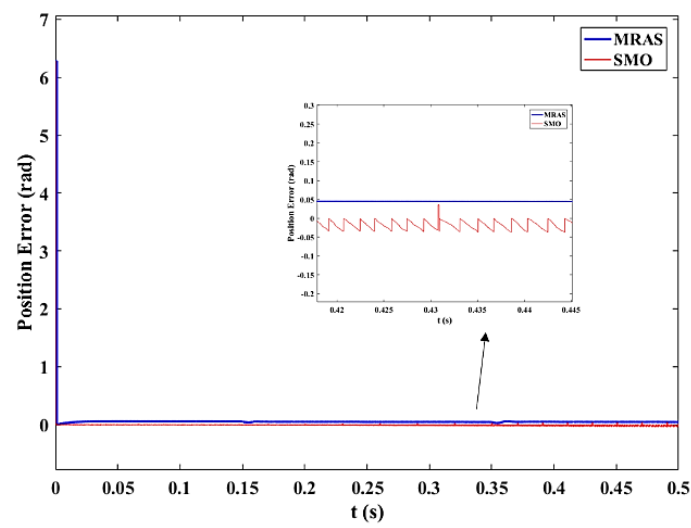

(d)

Figure 10. Speed, torque, phase currents and position error graphics of PMSM for 500-1000-1500 rpm and $5 \mathrm{Nm}$

In Fig. 10.a, when speed is increased from $500 \mathrm{rpm}$ to 1000 rpm at $0.15 \mathrm{~s}$, MRAS based control method speed response has $5 \%$ overshoot and SMO based control method has $3 \%$ overshoot. In Fig. 10.a and b, it is shown that in speed and torque curves SMO based model has more ripple than MRAS based model. As can be seen in Fig. 10.c, initial phase currents' values of MRAS is smaller than SMO. In Fig 10.d, position error in MRAS based control is 0.045 rad while in SMO based is $0.035 \mathrm{rad}$. SMO based model achieves fast response to load and speed variations but its settling time is more than MRAS model.
In Fig. 11, reference speed is $1000 \mathrm{rpm}$ and load torque is increased from 5 to $10 \mathrm{Nm}$ at $0.3 \mathrm{~s}$. In Fig. 11, it is shown that speed, torque, phase currents and position error simulation results of SMO and MRAS based models and their comparison.

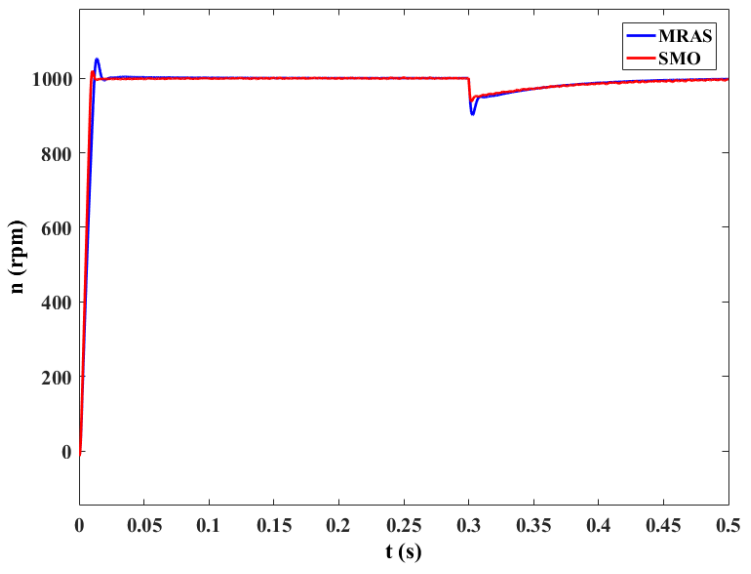

(a)

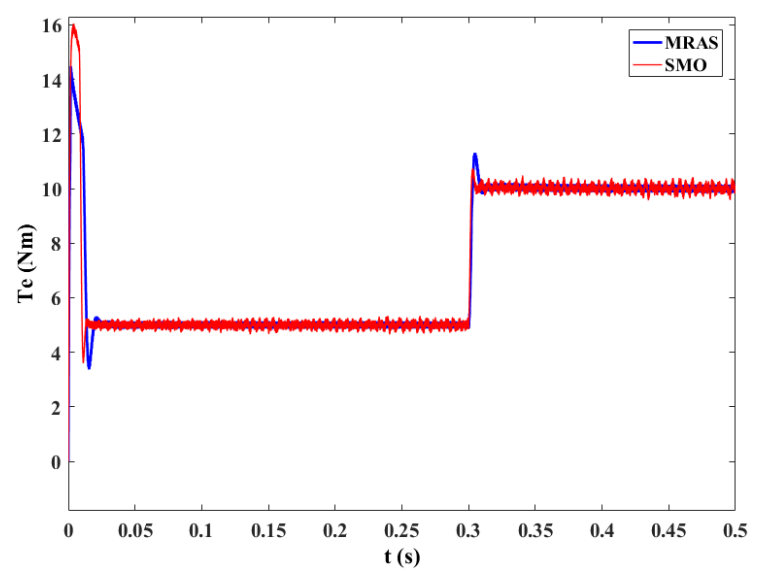

(b)

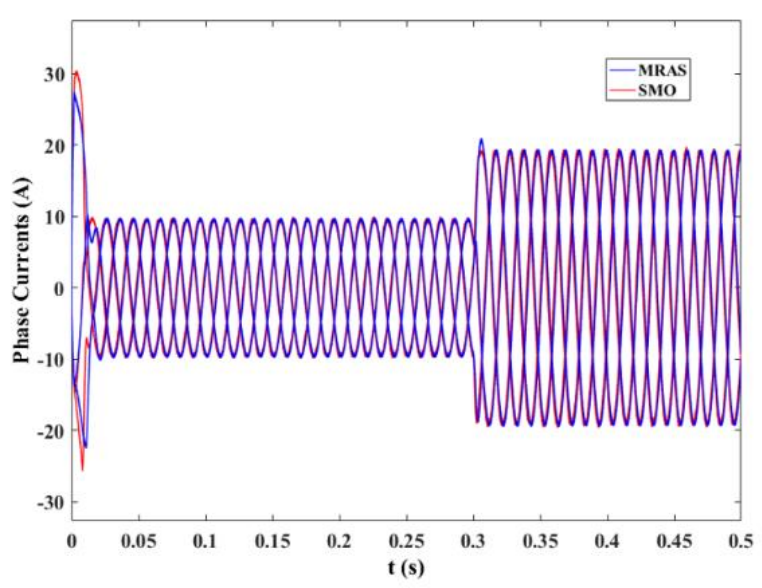

(c) 


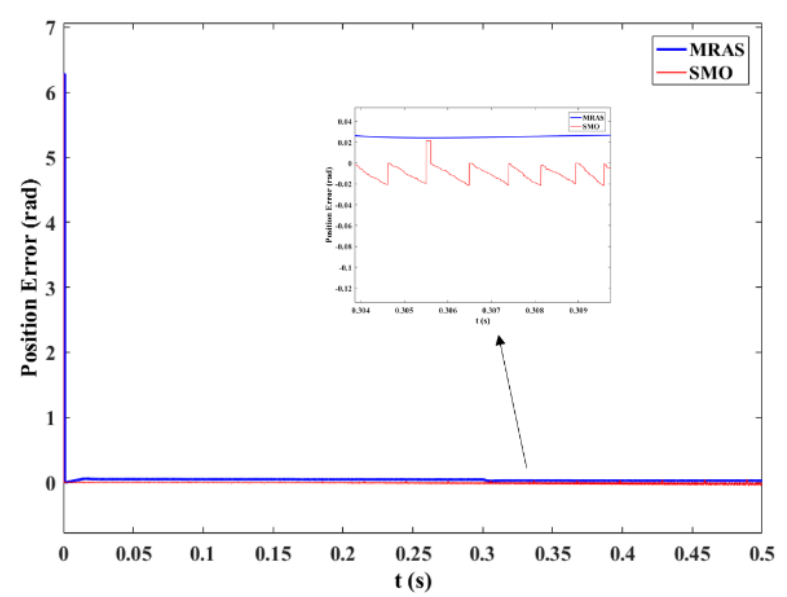

(d)

Figure 11. Speed, torque, phase currents and position error graphics of PMSM for $1000 \mathrm{rpm}$ and $5-10 \mathrm{Nm}$

In Fig. 11.a, MRAS based control method speed response has $5 \%$ overshoot and $0.03 \mathrm{~s}$ settling time while SMO based control method has $3 \%$ overshoot and 0.09 s settling time. In Fig 11.d, position error in MRAS based control is $0.025 \mathrm{rad}$ while in SMO based is $0.02 \mathrm{rad}$.

\section{CONCLUSION}

This paper presents a comparison between sensorless FOC of PMSM based on MRAS and SMO methods. Both of the models are able to track the reference values in different speed and load torque operations. But results show that MRAS based method has better dynamic response and higher performance. According to the simulation results in Fig 9.b, 9.c, 10.b, 10.c, 11.b and 11.c, it is observed that initial torque and current values in MRAS based model less than SMO based model. In Fig 9.a, 9.b, 10.a, 10.b, 11.a and 11.b, simulation results also proved that MRAS based model has better performance in terms of settling time and noise than that of SMO based model. As a result, the system is more stable and has less oscillation with the MRAS based method.

\section{REFERENCES}

[1] Blaschke, F., The principle of field-orientation as applied to the transvector closed loop control system for rotating-field machines:Siemens Rev., vol.34, no.1, pp. 217-220, 1972.

[2] Pillay, P., Krishnan, R., Modelling, simulation and analysis of permanent magnet motor drives. I. The permanent magnet synchronous motor drive, IEEE Trans. Industry applications, v.40, no.3, pp.265-273, 1989.

[3] Vas, P., Sensorless vector and direct torque control, Oxford University Press, pp.768., 1998.

[4] Rahman, M. A. and Slemon, G.R., Promising Applications of NdBFe Iron Magnets in Electrical Machines (Invited), IEEE Trans. On Magnetics, Vol. MAG-21, No. 5., 1985.

[5] Bojoi, R., Pastorelli, M., Bottomley, J., Giangrande, P., Gerada, C., Sensorless control of PM motor drives - A technology status review, Proc. - 2013 IEEE Work. Electr. Mach. Des. Control Diagnosis, WEMDCD , pp. 168-182., 2013

[6] Briz, F., Degner, M. W., García, P., and Lorenz, R. D., Comparison of saliency-based sensorless control techniques for AC machines, IEEE Trans. Ind. Appl., vol. 40, no. 4, pp. 1107-1115., 2004.
[7] Yongdong, L., Hao, Z., Sensorless control of permanent magnet synchronous motor - A survey, IEEE Veh. Power Propuls. Conf. VPPC.,2008.

[8] Holtz, J. Methods for speed sensorless control of AC drives, University of Wuppertal, Germany., 1996.

[9] Schrödl, M., Sensorless control of AC machines at low speed and standstill based on 'INFORM' method, IEEE Industry Applications Conference, IAS'96, vol. 1., 1996.

[10] Utkin, V., Sliding mode control design principles and applications to electric drive, IEEE Transactions On Industrial Electronics, Vol. 40, No.1., 1993.

[11] Drakunov, S., Utkin, V., Sliding mode observers tutorial, IEEE, Proceedings of the 34th conference on decision \& control, New Orleans., 1995.

[12] Kılıç, F., Model-free adaptive gain higher order sliding mode speed control of permanent magnet synchronous motor, Ph.D. Thesis, Kocaeli University, Applied Sciences Institutes., 2016.

[13] Yang, I., Lee, D., Han, D., Designing A Robust Nonlinear Dynamic Inversion Controller for Spacecraft Formation Flying, Mathematical Problems in Engineering Volume., 2014.

[14] Westin, I., Sensorless Control of a PMSM, MSc. Thesis, KTH Royal Instute of Technology School, Sweden., 2016.

[15] Kojabadi, H. M. , Ghribi, M., () MRAS-based adaptive speed estimator in PMSM drives, Int. Work. Adv. Motion Control. AMC, no. 1, pp. 569-572, 2006.

[16] Dursun, M., New model adaptive system design for sensorless speed control of PMSM, Publications Prepared for the Innovations on Intelligents Systems and Applications Symposium ASYU, Sigma J Eng \& Nat Sci 8 (2), 117-127., 2017

[17] Li, W. H. , Chen, Z. Y., Cao, W. P., Simulation research on optimization of permanent magnet synchronous motor sensorless vector control based on MRAS, Int. Conf. Wavelet Act. Media Technol. Inf. Process. ICWAMTIP, pp. 350-355., 2012.

\section{BIOGRAPHIES}

Çağlar Aydın obtained his BSc degree in electrical-electronics engineering from Ondokuz Mayıs University in 2015. He received the MSc. degree in electrical-electronics engineering from the Firat University in 2020. Currently, he is a PhD student at the Department of Electrical-Electronics Engineering of Firat University. His research interests are electrical machines and drive systems.

Sencer Ünal obtained his BSc degree in electrical-electronics engineering from Firat University in 1999. He received the MSc., and PhD. degrees in electrical-electronics engineering from the Frrat University in 2002 and 2009, respectively. He is currently Assistant Professor in Electrical and Electronics Engineering Department of Frrat University. His research interests are electrical machines, drive systems and power electronics.

Mehmet Özdemir was born in 1958 in Elazığ, Turkey. He obtained his BSc degree in electrical-electronics engineering in 1980. Then he received MSc. and $\mathrm{PhD}$. degrees in Electrical Engineering from Firat University in 1984 and 1993, respectively. He is currently Associate Professor in Electrical and Electronics Engineering Department of Firat University. His research interests are electrical machines and drives. 